\title{
MAGNESIUM-INDUCED MITOCHONDRIAL POLYMORPHISM AND CHANGES IN RESPIRATORY METABOLISM IN THE FISSION YEAST, SCHIZOSACCHAROMYCES POMBE
}

\author{
by \\ GRAEME M. WALKER ${ }^{1 *}$, AKSEL BIRCH-ANDERSEN ${ }^{2}$, \\ KIRSTEN HAMBURGER ${ }^{1}$ and BIRTE KRAMHØFT ${ }^{\prime}$ \\ ${ }^{1}$ Biological Institute of the Carlsberg Foundation, \\ Tagensvej 16, DK-2200 Copenhagen N \\ ${ }^{2}$ Statens Seruminstitut, Amager Boulevard, DK-2300 Copenhagen S \\ * Present address: Department of Biochemistry, \\ University of Otago, Box 56, Dunedin, New Zealand
}

Keywords: Schizosaccharomyces, respiration, fermentation, Mg-depletion, mitochondria

The role of magnesium ions in controlling mitochondrial structure and function in the fission yeast, Schizosaccharomyces pombe, has been studied. Results show that in control cultures of $\mathbf{S}$. pombe grown in the presence of magnesium, cells follow predominantly a fermentative pathway of metabolism. The mitochondria, as visualized by electron microscopy, are large but few in number, and appear irregularly branched with indistinct cristae. On depletion of the magnesium supply, cell division ceases after about 4 hours after which there is an increase in respiration. The mitochondria increase in number and become small with well-defined cristae. On replenishment of magnesium ions mitochondria seem to fuse and there is a gradual restoration of the respiratory metabolism characteristic of control cells.

\section{INTRODUCTION}

For many years, yeasts have served as a model system for studying aspects of mitochondrial structure and function. The fact that yeast cells are generally facultative anaerobes and are susceptible to catabolite repression has also made them amenable to physiological and genetic studies of mitochondrial biogenesis. Many studies have been carried out dealing with the effect of environmental parameters (including metal ions) on ultrastructure in mitochondria, but very few attempts have related alterations in ultrastructure to respiratory competance in microbial cells in vivo (9).

Magnesium is known to be important in maintaining mitochondrial structural integrity (for example ref. 5) and in energy yielding metabolism $(1,3,16)$. The present study is concerned with the role of magnesium ions in governing mito- 
chondrial structure and function in the fission yeast Schizosaccharomyces pombe.

\section{MATERIALS AND METHODS}

\subsection{Organism and culture conditions}

Schizosaccharomyces pombe, respiratorycompetent, glucose-repressible, haploid strain $972 \mathrm{~h}^{-}$, was originally obtained from Dr. JøRGEN FRIIS, University of Odense, Denmark and was grown at $32^{\circ} \mathrm{C}$ in Edinburgh Minimal Medium No. 2 (EMM 2) (12). Viable stock cultures were maintained by monthly subculturing at $32^{\circ} \mathrm{C}$ on EMM 2 agar slopes and storing at $4{ }^{\circ} \mathrm{C}$ when a sufficient number of colonies had formed. Experimental cultures were initiated by inoculating small volumes of actively dividing precultures into fresh EMM 2 and aerobically propagating in Erlenmeyer flasks in a shaking water bath at $32{ }^{\circ} \mathrm{C}$.

Magnesium free medium was prepared by omitting the $\mathrm{MgCl}_{2}$ component from the EMM 2 recipe and ensuring that only high purity reagents and fresh glass-distilled water constituted the remainder of the medium which was autoclaved in scrupulously clean Pyrex culture vessels. Such Mg-free EMM 2 contained an irreducible minimum trace level of around $0.2 \mu \mathrm{M}-\mathrm{Mg}$, as judged by flameless atomic absorption spectrophotometry.

\subsection{Cell number determination}

Cell numbers (the mean of 3-4 counts of 150200 cells) were determined using a Bürker-Türk hemocytometer employing the criterion of MITCHISON (12) in that a dividing cell is scored as two when the constriction is clearly observed between two daughter cells.

\subsection{Magnesium-depletion and refeeding}

Exponentially dividing cultures of $S$. pombe were harvested by Millipore membrane filtration ( $1.2 \mu \mathrm{m}$ pore size) and washed on the filter with distilled water. Washed cells were then resuspended in pre-warmed $\mathrm{Mg}$-free EMM 2 and propagated as described above. After a set period of "exhaustion", usually 24 hours, sufficient $\mathrm{MgCl}_{2}$ was added back to the culture to restore the magnesium level to that in normal EMM 2 (0.3 mM).

\subsection{Electron microscopy}

Cultures of S. pombe (generally 200-500 ml) were filtered and resuspended for 2 hours at 32 ${ }^{\circ} \mathrm{C}$ in glutaraldehyde fixation buffer: $2 \%$ glutaraldehyde, 1 mM-GTP (guanosine triphosphate), 1 mM- $\mathrm{MgSO}_{4}, 2$ mM-EGTA (Ethyleneglycol-bis( $\beta$-aminoethyl ether)-N,N'-tetraacetic acid) and $100 \mathrm{~mm}$-PIPES (1,4-Piperazinediethane sulfonic acid) $\mathrm{pH} 6.9$ (11). After fixation, cells were washed thrice with warm $\left(32^{\circ} \mathrm{C}\right)$ distilled water and the pellet mixed with approximately five times its volume of glass beads $(0.45-0.50 \mathrm{~mm}$ diameter) (13). After vortex mixing for $10-15 \mathrm{sec}$, the cells were resuspended in $10 \mathrm{ml}$ distilled water. The glass beads were allowed to settle before the supernatant was decanted and the cells pelleted by centrifugation at $2500 \mathrm{rpm}$ in an MSE Mistral centrifuge. Cells were then postfixed at room temperature in $1 \%$ osmium tetroxide in cacodylate buffer ( $\mathrm{pH} \mathrm{7.2)}$ for $30 \mathrm{~min}$, washed twice with distilled water and treated with $5 \mathrm{ml} 2 \%$ uranyl acetate in distilled water at room temperature for $30 \mathrm{~min}$. Cells were again washed twice and finally dispersed in $1 \mathrm{ml}$ melted $1.5 \%$ Noble Agar (Difco) in cacodylate buffer which had been cooled to $45^{\circ} \mathrm{C}$. After centrifugation as above at $45^{\circ} \mathrm{C}$ the agar pellets with cells layered in them were stored at $4{ }^{\circ} \mathrm{C}$ over night. In general 3 distinct cell layers could be distinguished in the solidified agar block and samples of each layer were examined by light microscopy in order to select the region in which cells with obviously fractured cell walls were dominating. From this layer small blocks $\left(1 \mathrm{~mm}^{3}\right)$ were made and dehydrated in increasing concentrations of alcohol followed by propylene oxide (10) prior to embedding in Vestopal-W (15). Thin sections of blocks were cut with glass knives on an LKB ultrotome III microtome and double stained with magnesium uranyl acetate (6) and lead citrate (14). The sections were examined in a Phillips 300 electron microscope at $60 \mathrm{kV}$. Exposures were made on $35 \mathrm{~mm}$ Kodak Fine Grain Release Positive film Type 5302 at primary magnifications of $1500 \times$ and $9000 \times$, and prints were obtained after photographic enlargement as desired.

\subsection{Respiration and fermentation}

Gaseous exchanges (uptake of $\mathrm{O}_{2}$ and produc- 
tion of $\mathrm{CO}_{2}$ ) were assessed using the Warburg technique. Details of this method when applied to cultures of Schizosaccharomyces have been described elsewhere (7). The oxygen consumption of control cells was found to be $1.5 \mu \mathrm{l} \cdot \mathrm{h}^{-1} \cdot 10^{-6}$ cells and the total $\mathrm{CO}_{2}$ production 13.6 $\mu \mathrm{l} \cdot \mathrm{h}^{-1} \cdot 10^{-6}$ cells; the RQ (the ratio of total $\mathrm{CO}_{2}$ produced to $\mathrm{O}_{2}$ uptake) thus equalled 9 , in agreement with previous results (8).

\section{RESULTS}

\subsection{Morphological studies}

As has been previously reported by WALKER and Duffus (17) S. pombe cells divide about once in magnesium-free minimal medium, then cease dividing. Inhibition of cell division is associated with a failure of cells to complete mitosis, septum formation and cytokinesis. Cells will, however, continue to grow and synthesize protein (cf Figure 7, open circles) and appear abnormally elongated after prolonged periods of magnesium-deficiency. Light microscopy reveals many enlarged vacuoles in the cytoplasm of the cells (17).

In the present study structural changes induced in Mg-deficient media were monitored by electron microscopy, and striking alterations were revealed in the number, location and morphology of mitochondria in comparison with control cells from normal Mg levels. In addition, the cytoplasm of magnesium-deficient cells contains greatly increased numbers of vacuolar inclusions which often appear as an annulus around the nucleus (Figures 3 and 4). Mitochondria in control cells characteristically appear long and branched with occasional “horse-shoe" configurations proximal to the nucleus (Figures 1 and 2). Control cells normally contain 4 of these mitochondria (4) in which cristae are rather poorly defined. By contrast, if cells are specifically depleted of magnesium for 24 hours, the cytoplasm appears packed with numerous small, round mitochondria with well defined cristae (Figures 3 and 4).

On restoration of the magnesium supply, depleted cells recommence division after a lag as shown previously (17) and in Figure 8, lower set of curves. If cells are fixed and examined at progressive stages during this recovery we can observe associated changes in mitochrondrial ultrastructure. It appears that mitochondria gradually revert to a more reticular type of morphology with less well-defined cristae (Figures 5 and 6) and that individual organelles fuse to produce the configurations found in control cells.

\section{LEGENDS TO FIGURES}

The electron micrographs, Figures 1-6, all show parts of cells of the fission yeast Schizosaccharomyces pombe. The sections were poststained with magnesium uranyl acetate and lead citrate. A double bar $(=)$ on a micrograph represents $1 \mu \mathrm{m}$ and a single bar (-) $0.1 \mu \mathrm{m}$.

Figures $1 \mathrm{~A}$ and B. Longitudinal sections of cells grown in the presence of magnesium.

The mitochondria are long and branched and appear to be located proximal to the cell nuclei. 15,000 $\mathrm{x}$.

Figure 2. A higher magnification of part of a longitudinal section through another control cell grown in magnesium-containing medium.

Note the long and slender mitochondrion in the matrix of which cristae are almost indistinguishable. The mitochondrial outer membrane (MO) is well defined and so is the nuclear membrane (NM). R denotes ribosomes in the cytoplasm and CL the cortical layer of membranes. This particular cell has completely lost its cell wall during treatment with glass beads. $90,000 \times$.

Figures $3 \mathrm{~A}$ and $\mathrm{B}$. One longitudinally and two cross sectioned cells.grown in medium depleted of magnesium for 24 hours.

Note that the cytoplasm is packed with small round mitochrondria. An increased number of vacuolar inclusions is seen in one of the cross sectioned cells which apparently is sectioned close to the nucleus. 15,000 $\mathrm{x}$.

Figure 4. A higher magnification of part of a cell grown in medium depleted of magnesium for 24 hours.

The well defined cristae (CR) of the small mitochondria are clearly shown. R denotes ribosomes. 90,000 x. 
G. M. WALKER et al.: Respiration and mitochondrial structure
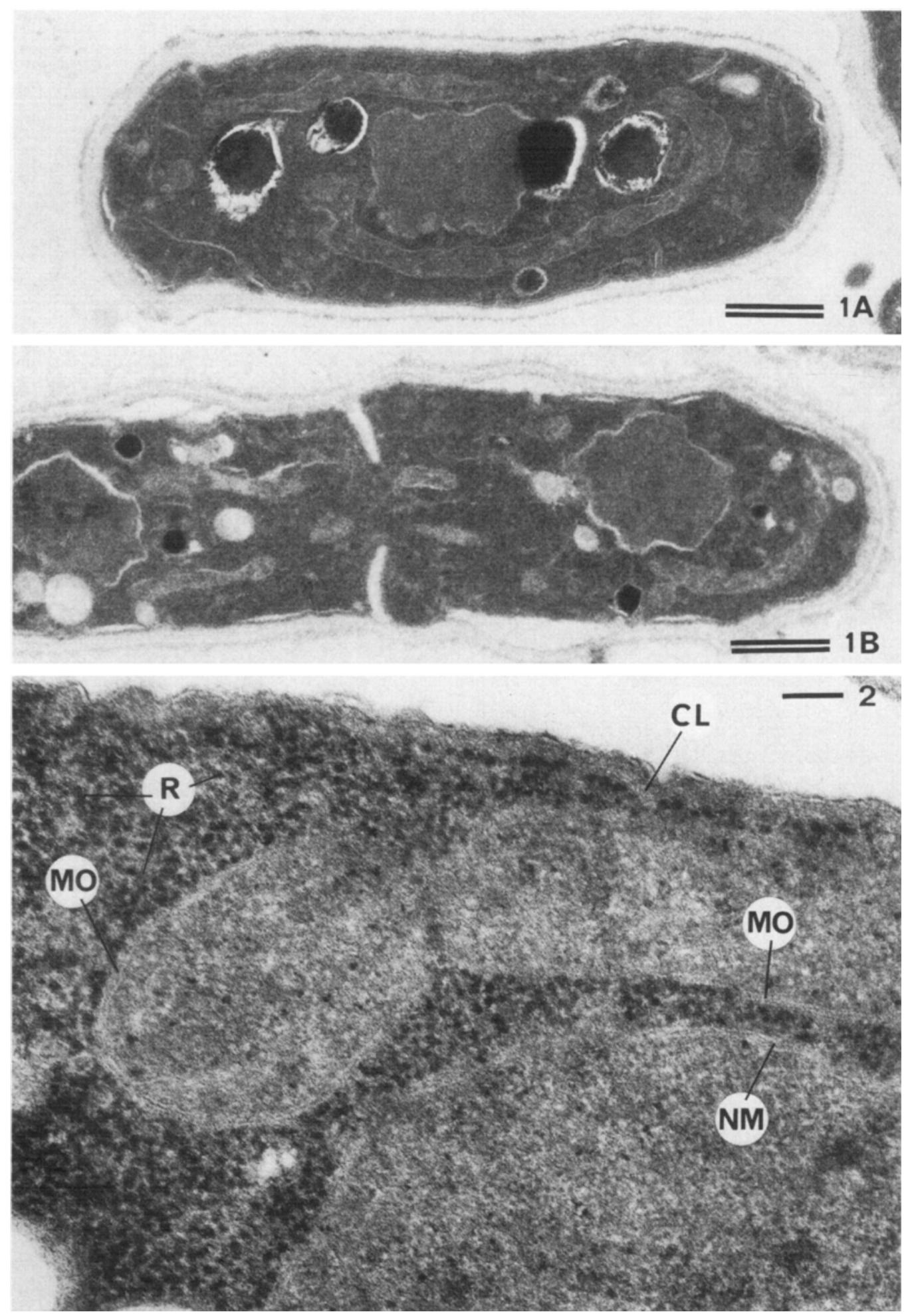


\section{G. M. WALKER et al.: Respiration and mitochondrial structure}
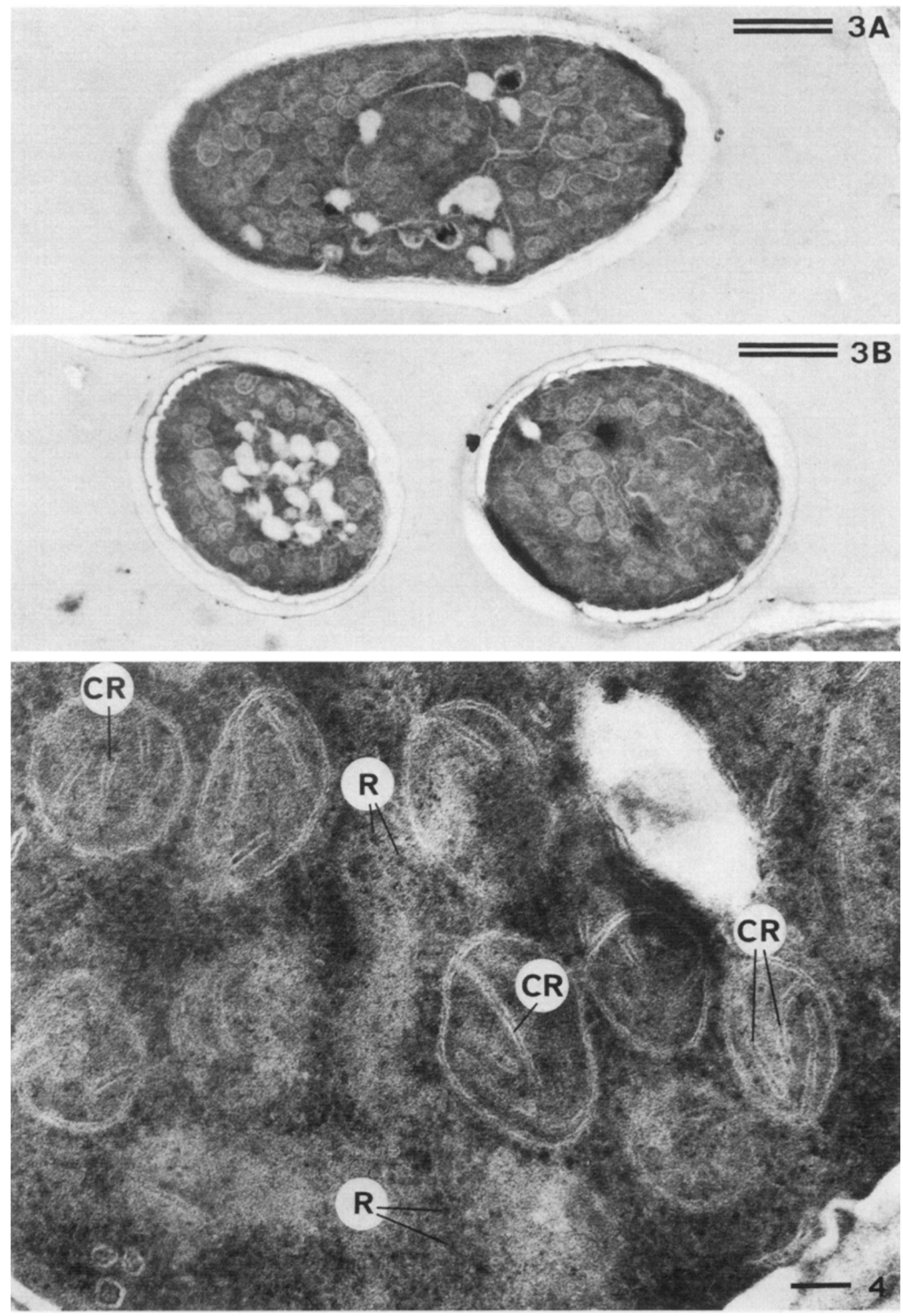

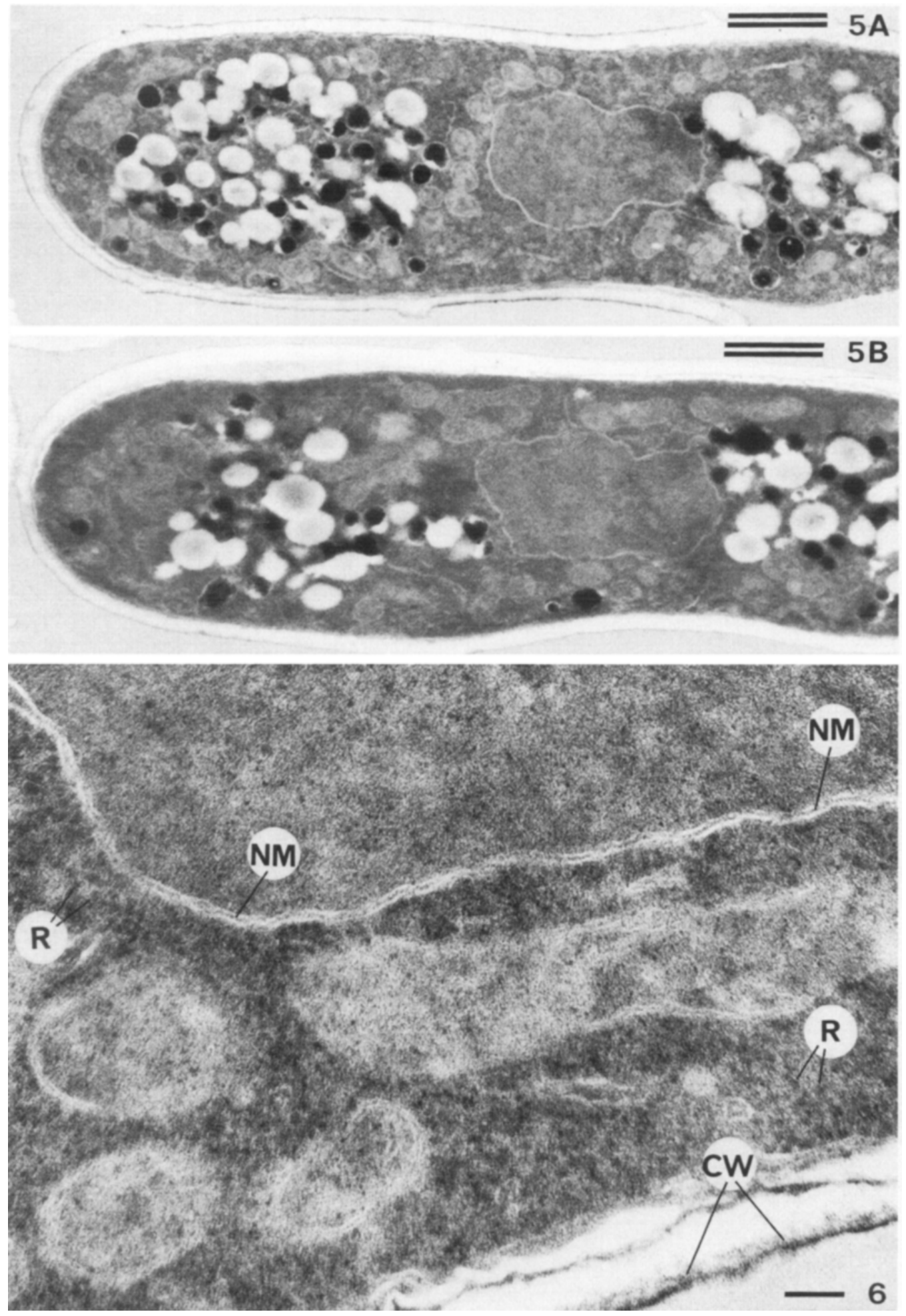


\subsection{Respiratory metabolism studies}

In conjunction with these ultrastructural studies, experiments were carried out to examine concomitant changes in respiration and fermentation on depleting and refeeding with magnesium. In normally dividing control cells of $S$. pombe, the respiratory quotient, $R Q$, was found to remain constant at about $9(8)$. As cells are propagated in magnesium-deficient medium, the $\mathrm{O}_{2}$ uptake (Figure 7, closed squares), the $\mathrm{CO}_{2}$ production (open squares) and hence the $R Q$ (triangles) remain unchanged in the initial 4-5 hours as long as cell division continues (closed circles). After cessation of cell multiplication, however, the $\mathrm{O}_{2}$ uptake increases and the $\mathrm{CO}_{2}$ production decreases causing a decrease in the RQ. After about 12 hours without magnesium, the RQ has dropped to between 2 and 3, while at 24 hours the RQ is about 1 (cf Figure 8, triangles), which indicates a fully aerobic metabolism.

Experiments in which magnesium was added back to cultures depleted for 24 hours revealed a transient decrease (1-2 hours) in the rate of oxygen uptake of about $25 \%$ immediately after readdition of magnesium (Figure 8, closed squares). As shown (open squares) the rate of $\mathrm{CO}_{2}$ production increases abruptly about 1 hour after the addition, resulting in a gradual increase in RQ (triangles). After about 9 hours full recovery of the fermentation was observed.

\section{DISCUSSION}

It has been emphasized that the dynamic nature of mitochondria and the number and organization of these organelles depend on many factors including the oxygen and nutrient supply (9). Certainly, the dramatic change in mitochondrial organization seen in the present study on limiting the magnesium supply serves to focus attention on this cation in addition to other known environmental effectors.
Results relating changes in respiratory metabolism with mitochondrial ultrastructure correlate with changes in magnesium supply. As shown (Figures 3,4 and 7) magnesium depleted cells with the characteristic cristate mitochondrial profile display a characteristic respiratory capacity $(R Q=1)$ whereas cells grown in normal medium have large mitochondria with indistinct cristae, and show a high fermentative capacity (high RQ). Thus, the magnesium induced changes in mitochondrial ultrastructure appear to reflect a switch from a fermentative to a respiratory mode of metabolism.

These effects of magnesium deficiency on mitochondrial polymorphism may be related to the importance of this ion in the regulation of cellular metabolism, as stated by BYgrave (3). Thus, the activity of the key enzymes of glycolysis (hexokinase, phosphofructokinase and pyruvate kinase) depends upon the magnesium concentration; however, magnesium is also necessary for the maintenance of the structural integrity of biomembranes in general. Dow et al. (5) have reported a correlation between magnesium supply and mitochondrial swelling and contraction, and Lloyd (9) has noted that magnesium is necessary to maintain mitochondrial integrity during cell breakage. Our results suggest greater dependency on magnesium of the enzymes of glycolysis than of those of respiration, or alternatively, a stronger tendency for magnesium to become membrane associated than to bind to soluble enzymes. This latter suggestion is supported by the finding of BALTSCHEFFSKY of in vitro strong binding of magnesium to mitochondria (1).

The magnesium depleted cells appear to contain increased amounts of lipid deposits which could be employed for fat catabolism under conditions of magnesium deficiency. It is therefore conceivable that magnesium starved cells obtain

Figures $5 \mathrm{~A}$ and B. Longitudinal sections of two cells grown after restoration of the magnesium supply of the medium.

Note that the mitochondria are smaller than those of control cells, but that they appear to align as if preparing for fussion. $15,000 \mathrm{x}$.

Figure 6. A higher magnification of part of a cell grown after restoration of the magnesium supply of the medium.

The cristae of the mitochondria are ill-defined in the rather dense matrix. Ribosomes (R) are numerous and the nuclear membrane (NM) is well-defined. $\mathrm{CW}$ denotes cell wall. $90,000 \times$. 


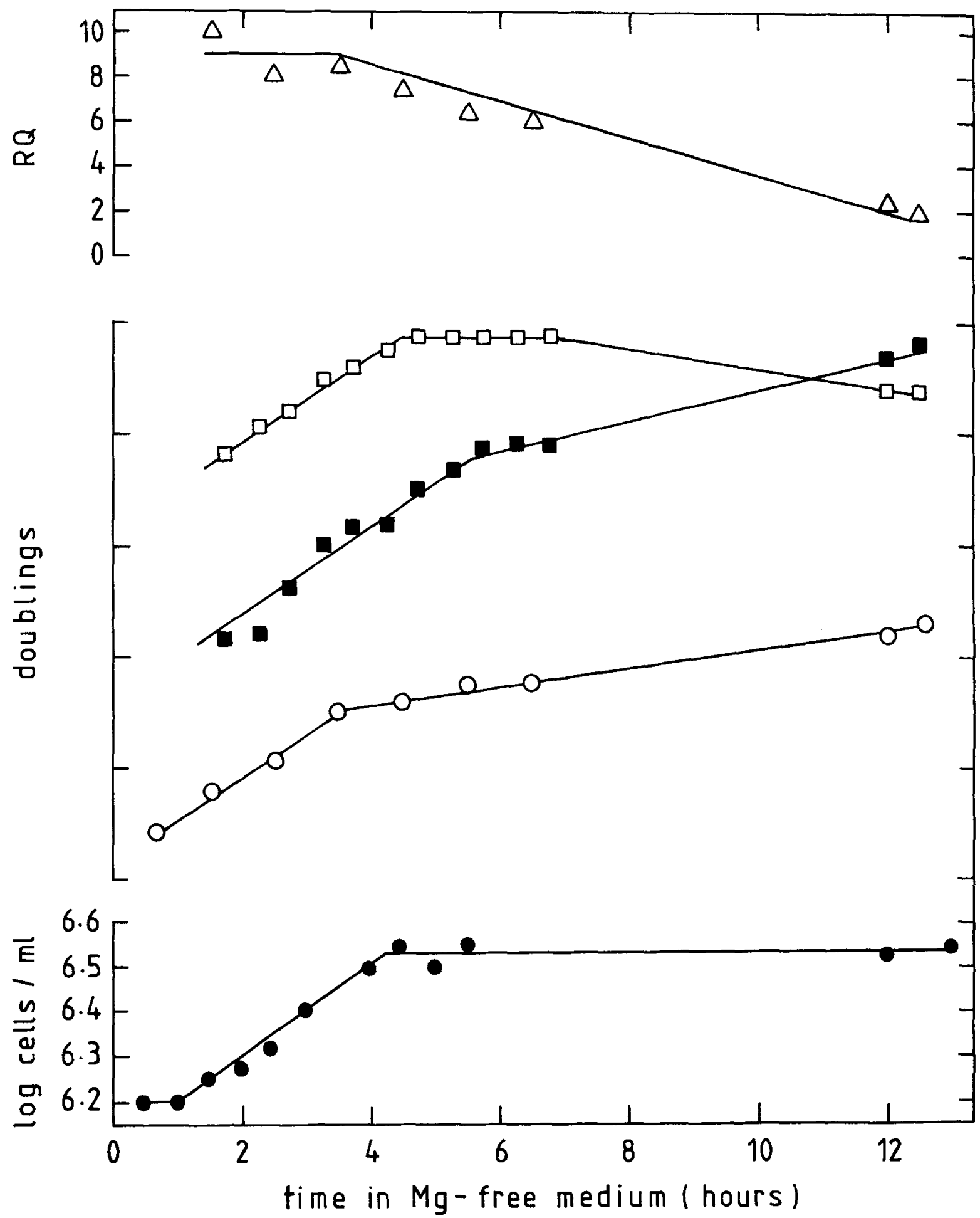

Figure 7. Cell division, growth and respiratory metabolism in $\mathrm{S}$. pombe during magnesium deficiency.

At zero time, washed cells were resuspended in magnesium-free medium and propagated at $32^{\circ} \mathrm{C}$. number, $O$ : protein $\left(\mu \mathrm{g} \cdot \mathrm{ml}\right.$ cell suspension $\left.{ }^{-1}\right), \mathbf{\square}: \mathrm{O}_{2}$ uptake $\left(\mu \mathrm{l} \cdot \mathrm{ml}\right.$ cell suspension $\left.{ }^{-1}\right), \square: \mathrm{CO}_{2}$ release $(\mu \mathrm{l}$ $\mathrm{ml}$ cell suspension $\left.{ }^{-1}\right), \triangle: \mathrm{RQ}$. 
their energy by fatty acid oxidation which might have a lower magnesium requirement than glycolysis.

\section{ACKNOWLEDGEMENTS}

The authors wish to thank LISBETH FALDBORG Petersen, Helene Ravn and Helga Sørensen

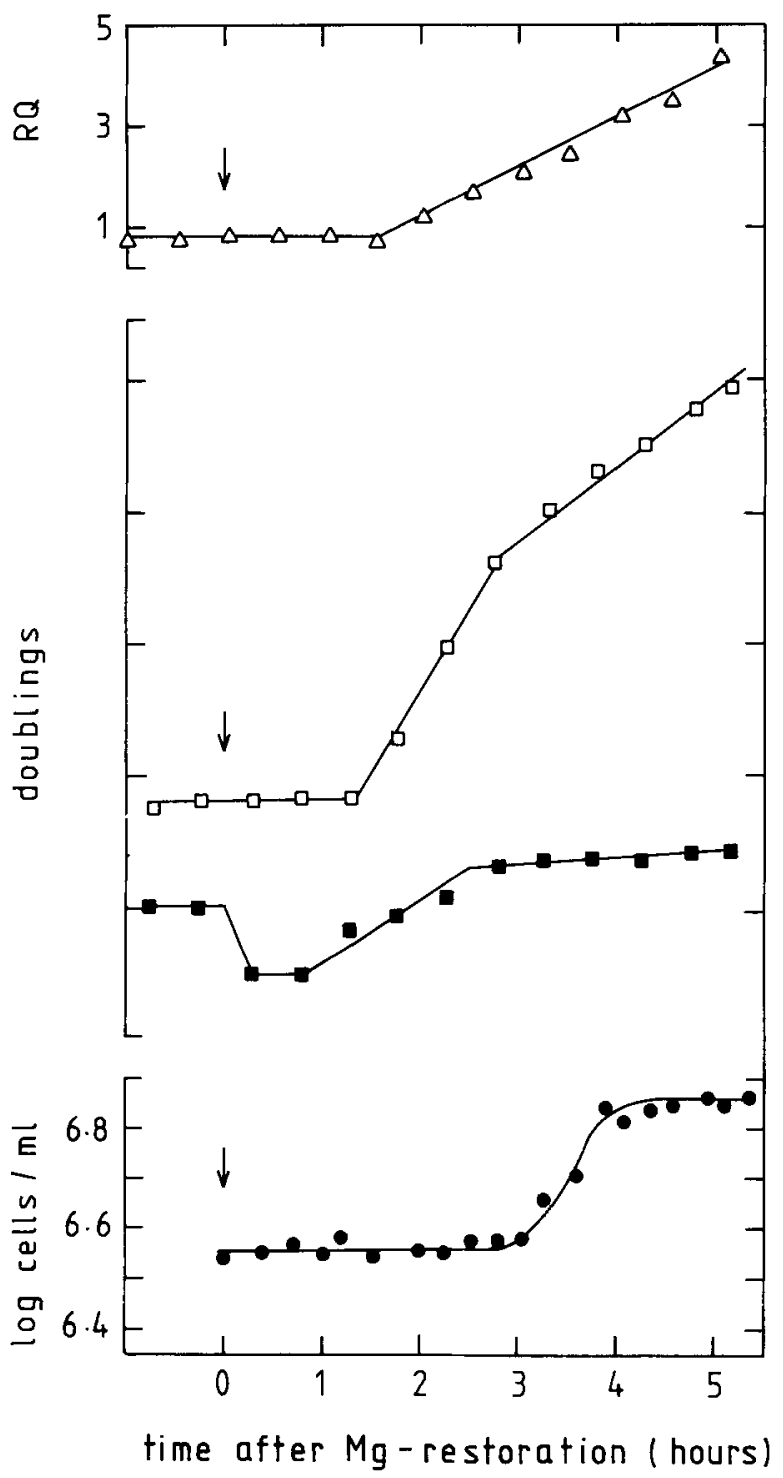

Figure 8. Cell division and respiratory metabolism in a $\mathrm{Mg}$-depleted culture of $\mathrm{S}$. pombe to which $\mathrm{Mg}$ was restored at time zero (arrow).

The cells were starved for 24 hours. Symbols as in Figure 7. for excellent technical assistance, and FINN LAURSEN and A. G. OvERGAARD for the photographic work especially on the illustrations.

Graeme M. WALKer was supported by a Royal Society/British Science Research Council Postdoctoral Fellowship, funded by the NATO Science Fellowship Programme.

\section{REFERENCES}

1. BALTSCHEFFSKY, H.: Mitochondrial respiratory control and phosphorylative activities in a magnesium-free medium. Biochem. Biophys. Acta 25, 382-388 (1957)

2. BRIERLEY, G. P.: The uptake and extrusion of monovalent cations by isolated heart mitochondria. Mol. Cell. Biochem. 10, 41-62 (1976)

3. Bygrave, F. J.: The ionic environment and metabolic control. Nature 214, 667-671 (1976).

4. Davison, M. T. \& P. B. Garland: Structure of mitochondria and vacuoles of Candida utilis and Schizosaccharomyces pombe studied by electron microscopy of serial thin sections and model building. J. Gen. Microbiol. 98, 147-153 (1977).

5. Dow, D. S., K. G. Walton \& S. Fleischer: Control of mitochondrial swelling by $\mathrm{Mg}^{2+}-$ the relation of ion transport to structural changes. J. Bioenerget. 1, 247-271 (1970).

6. Frasca, J. M. \& V. R. Parks: A routine technique for double staining ultrathin sections using uranyl and lead salts. J. Cell Biol. 25, 157-161 (1969).

7. Hamburger, K., B. Kramhøft, S. B. Nissen \& E. ZEUTHEN: Linear increase in glycolytic activity through the cell cycle of Schizosaccharomyces pombe. J. Cell Sci. 24, 69-79 (1977).

8. KramhøFt, B., K. Hamburger, S. B. Nissen \& E. Zeuthen: The cell cycle and glycolytic activity of Schizosaccharomyces pombe synchronized in defined medium. Carlsberg Res. Commun. 43, 227-239 (1978).

9. LLoYd, D.: The mitochondria of microorganisms. Academic Press (1974).

10. LuFT, J. H.: Improvements in epoxy resin embedding methods. J. Biophys. Biochem. Cytol. 9, 409-414 (1961).

11. Luftig, R. B., P. N. McMillan, J. A. WeAtherbee \& R. R. Weihing: Increased visualization of microtubules by an improved fixation procedure. J. Histochem. Cytochem. 25, 175-187 (1977).

12. Mitchison, J. M.: Physiological and cytologi- 
cal methods for Schizosaccharomyces pombe. In: Methods in Cell Physiology Vol. IV (D.M. Prescott, ed.) Academic Press, pp 131-165 (1970).

13. Olson, L. W. \& U. M. Edén: A glass bead treatment facilitating the fixation and infiltration of yeast and other refractory cells for electron microscopy. Protoplasma 91, 417-420 (1977).

14. Reynolds, E. S.: The use of lead citrate at a high $\mathrm{pH}$ as an electron opaque stain in electron microscopy. J. Cell Biol. 17, 208-212 (1968).

15. Ryter, A.\& E. Kellenberger: Linclusion au polyester pour l'ultramicroscopie. J. Ultrastruct. Res. 2, 200-214 (1958).

16. Vitale, J. J., M. Nakamura \& D. M. HegSTED: The effect of magnesium deficiency on oxidative phosphorylation. J. Biol. Chem. 228, 573-576 (1957).

17. Walker, G. M. \& J. H. Duffus: Magnesium ions and the control of the cell cycle in yeast. $J$. Cell Sci. 42, 329-356 (1980). 